\title{
Effects of stratified active layers on high-altitude permafrost warming: a case study on the Qinghai-Tibet Plateau
}

\author{
Xicai Pan ${ }^{1}$, Yanping $\mathrm{Li}^{1}$, Qihao $\mathrm{Yu}^{2}$, Xiaogang Shi ${ }^{3}$, Daqing Yang ${ }^{4}$, and Kurt Roth ${ }^{5}$ \\ ${ }^{1}$ Global Institute for Water Security, University of Saskatchewan, 11 Innovation Boulevard, Saskatoon, SK S7N 3H5, Canada \\ ${ }^{2}$ Laboratory of Frozen Soils Engineering, Cold and Arid Regions Environmental and Engineering Research Institute, Chinese \\ Academy of Sciences, Donggang West Road 320, Lanzhou, 730000, China \\ ${ }^{3}$ CSIRO Land and Water, Christian Laboratory, Clunies Ross Street, Black Mountain, Canberra, Australian Capital Territory, \\ 2601, Australia \\ ${ }^{4}$ National Hydrology Research Centre, Environment Canada, 11 Innovation Boulevard, Saskatoon, SK S7N 3H5, Canada \\ ${ }^{5}$ Institute of Environmental Physics, Heidelberg University, Im Neuenheimer Feld 229, Heidelberg, 69120, Germany
}

Correspondence to: Yanping Li (yanping.li@usask.ca)

Received: 23 November 2015 - Published in The Cryosphere Discuss.: 18 January 2016

Revised: 30 June 2016 - Accepted: 5 July 2016 - Published: 25 July 2016

\begin{abstract}
Seasonally variable thermal conductivity in active layers is one important factor that controls the thermal state of permafrost. The common assumption is that this conductivity is considerably lower in the thawed than in the frozen state, $\lambda_{\mathrm{t}} / \lambda_{\mathrm{f}}<1$. Using a 9-year dataset from the QinghaiTibet Plateau (QTP) in conjunction with the GEOtop model, we demonstrate that the ratio $\lambda_{\mathrm{t}} / \lambda_{\mathrm{f}}$ may approach or even exceed 1. This can happen in thick $(>1.5 \mathrm{~m})$ active layers with strong seasonal total water content changes in the regions with summer-monsoon-dominated precipitation pattern. The conductivity ratio can be further increased by typical soil architectures that may lead to a dry interlayer. The unique pattern of soil hydraulic and thermal dynamics in the active layer can be one important contributor for the rapid permafrost warming at the study site. These findings suggest that, given the increase in air temperature and precipitation, soil hydraulic properties, particularly soil architecture in those thick active layers must be properly taken into account in permafrost models.
\end{abstract}

\section{Introduction}

Along with climate warming, permafrost warming has been widely observed in the Arctic and sub-Arctic as well as in midlatitude alpine regions like the Alps and the Tibetan Plateau (Romanovsky et al., 2013; Harris et al., 2009;
Cheng and $\mathrm{Wu}, 2007)$. Permafrost thaw has caused considerable changes for surface and subsurface hydrologic routing (Kurylyk et al., 2014), geotechnical failures (Harris et al., 2009) and carbon dioxide and methane release (Schuur et al., 2015). Therefore, understanding permafrost warming is essential to cope with such consequences. The mean annual ground temperature (MAGT) at a depth of zero annual amplitude is often used to indicate permafrost warming (e.g. Wu et al., 2012). The warming rate is controlled by a variety of factors such as weather regimes, geography/geology and ecosystems. Generally, cold permafrost has a higher warming rate than warm permafrost (Wu et al., 2012). However, permafrost temperature can differ greatly in the same region due to local factors like topography, soil properties and vegetation. Responses of permafrost controlled by these local factors to climate change is thus also expected to differ. For instance, the permafrost along the Qinghai-Xizang (Tibet) railway experienced a mean warming rate of $0.02^{\circ} \mathrm{C} \mathrm{yr}^{-1}$ at a depth of $6.0 \mathrm{~m}$ over the period from 2006 to 2010 , and the highest warming rate even reached $0.08^{\circ} \mathrm{C} \mathrm{yr}^{-1}$ in the Fenghuo Mts. area (Wu et al., 2012). Given the same change in climate variables, these local factors still cause the underlying permafrost to develop differently. For instance, one recent study in the central QTP shows that permafrost at 10 sites experienced highly differing warming rates over the period of 2002-2014 (Wu et al., 2015). Compared to the rate of $0.03^{\circ} \mathrm{Cyr}^{-1}$ for the past 5 decades over the QTP (Piao et 
al., 2010), there was no extraordinary increase in air temperature $\left(0.02{ }^{\circ} \mathrm{C} \mathrm{yr}^{-1}\right)$ at the investigated area. Thus, an average increasing rate of $0.01{ }^{\circ} \mathrm{C} \mathrm{yr}^{-1}$ at $10 \mathrm{~m}$ depth in permafrost temperature sounds rather high. Wu et al. (2015) suggested that this was due to the increasing rainfall and the asymmetrical seasonal changes in subsurface soil temperatures. Under the warming of the atmosphere, the high warming rate of the permafrost is even similar to that of air temperature rise, $0.02{ }^{\circ} \mathrm{C} \mathrm{yr}^{-1}$. Thereby, we expect a dominating role of subsurface processes in the active layer that amplify the climate warming input.

As a buffer layer, the active layer regulates the energy transfer between the atmosphere and permafrost in addition to vegetation and snow cover. In this study, we focus on the high-altitude permafrost on the QTP, which is characterized by a thick unsaturated active layer and sparsely vegetated surface. In contrast to the commonly thin active layers in the Arctic, the active layers on the QTP are usually over $1.5 \mathrm{~m}$ thick, and soil architectures consist of a fine-grained layer without (or only thin) surface organic horizons overlaying coarse immature soils, which is characterized as low content of fine-grained materials like silt and clay (Huang et al., 2006). These stratified active layers are commonly found on the QTP along with a dry interlayer between top soil and bottom soil. Furthermore, with precipitation concentrated in the summer season as rainfall, the subsurface soil hydraulic properties play an important role in ground heat transfer due to seasonal soil moisture change (e.g. Hayashi et al., 2007). In contrast to the well-studied permafrost in the Arctic, the applicability of the analytic models of the climate-permafrost relationship based on the seasonally variable thermal conductivity might be challenging. For instance, thermal offset was firstly identified as higher mean annual temperature in the upper portion of the active layer than in the underlying permafrost by Burn and Smith (1988) at several sites in Yukon, Canada and it is attributed to the difference between frozen and thawed thermal conductivities of the soil. Then a model of thermal offset effect is proposed to link ground surface temperature to mean annual temperature at the top of the permafrost table (TTOP) (Romanovsky and Osterkamp, 1995). Based on this concept, the TTOP is estimated using the TTOP model developed by Smith and Riseborough (1996, 2002), which also uses surface offset that links air temperature to ground surface temperature. Normally, a wet active layer has a larger thermal offset than a dry active layer, which has small or even vanishing thermal offset (e.g. Romanovsky and Osterkamp, 1995; Hasler et al., 2011). However, a reversed thermal offset, namely TTOP > MAGST, has been reported by Lin et al. (2015) on the QTP. To evaluate the applicability of this concept, further exploration of the hydraulic and thermal mechanisms in the active layers on the QTP is required. This might enable us to understand the impact of the active layer on permafrost warming.
In this study, we use observations over a 9-year period and numerical simulations to investigate recent permafrost warming at a site in a warm permafrost region on the QTP and to demonstrate the role of a typical stratified active layer in permafrost warming. Our goals are (1) to characterize the rapid permafrost warming at the study site, (2) to reveal the unique phenomenon of the reversed seasonally variable thermal conductivity in the active layer that challenges the application of the analytic models by comparing with observations and physically based modelling and (3) to emphasize the importance of incorporating structural soil hydraulic properties in permafrost projections given a rain-dominated weather pattern on the QTP.

\section{Material and methods}

\subsection{Site descriptions}

The Chumaer site is located on a high plain of the Chumaer River catchment in the north-eastern QTP with an average altitude of over $4450 \mathrm{~m}$ (Fig. 1). In the catchment area, the land surface is covered by bare soil or sparse vegetation. Measurements at the study site comprise a monitoring station and several boreholes, with discontinuous ground temperature measurements since 2006 (Pan et al., 2014). The monitoring station has been complemented by soil-weather measurements since 2006. The weather data from 2006 to 2014 show an average air temperature of about $-16.0^{\circ} \mathrm{C}$ in January and $7.2^{\circ} \mathrm{C}$ in July, and precipitation is dominated by summer monsoon from June to September, which brings about $350 \mathrm{~mm}$ precipitation annually, falling mostly as rainfall. Irregular thin snow cover occurs in late spring or early winter, lasting usually just a few weeks. The stratigraphy includes a fine top soil $(30 \mathrm{~cm})$ and a middle layer of alluvial sandy and gravelly sediment up to $3 \mathrm{~m}$ that lies over deeply weathered mudstone. The borehole data indicate that the permafrost has a thickness about $25 \mathrm{~m}$, and the temperature at a depth of $10 \mathrm{~m}$ is less than $-1.0^{\circ} \mathrm{C}$. The active layer thickness is around $2.5 \mathrm{~m}$.

\subsection{Surface-subsurface monitoring scheme}

The surface-subsurface interaction has been investigated since 2006. Regular meteorological variables including air temperature, precipitation, relative humidity, wind speed and direction and net radiation were monitored at an automatic weather station. Subsurface hydraulic and thermal dynamics within the active layer were monitored by measuring soil temperature and soil water content at a variety of depths (soil temperature: $0.05,0.10,0.15,0.20,0.30,0.50,0.70,0.90$, $1.10,1.30,1.50,1.70,1.92,2.08,2.18,2.30,2.50,2.70,3.00$, 3.30, $3.60 \mathrm{~m}$; soil water content: $0.10,0.20,0.40,0.65,0.89$, $1.19,1.54,1.92,2.10 \mathrm{~m})$. They were recorded with a time interval of $60 \mathrm{~min}$. Soil temperature was measured with thermistors, which provides an accuracy of $0.05^{\circ} \mathrm{C}$. Liquid soil 


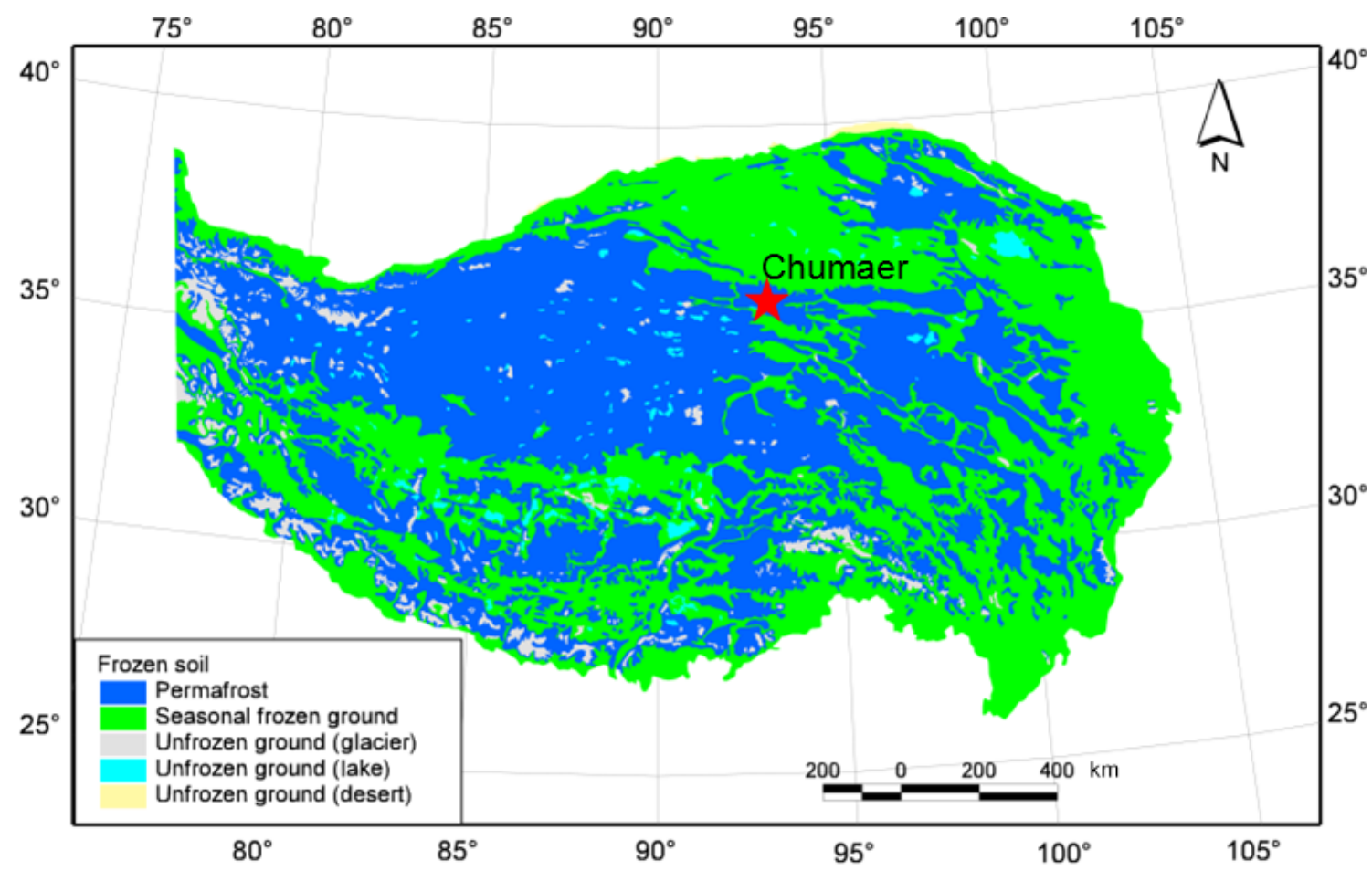

Figure 1. Study site location and permafrost distribution on the Qinghai-Tibet Plateau. The background map shows the permafrost classes from Li and Cheng (1996).

water content was measured with CS616 sensors (Campbell Scientific Ltd.), and the total water content in frozen soils was deduced from the value measured just before freezing. Here we assume negligible soil water redistribution during freezing due to the coarse soils. Thus, its accuracy is around $\pm 5 \%$ (Pan, 2011). More detailed technical description of the instrumentation can be found in Pan (2011). In addition, permafrost temperature was investigated with two boreholes about $30 \mathrm{~m}$ away in a flat area. The shallow borehole is $15 \mathrm{~m}$ in depth and the deep one is $60 \mathrm{~m}$, which penetrates through the permafrost.

\subsection{GEOtop model}

GEOtop (version: 1.45), used in this study, is a processbased energy and mass-balance model (Rigon et al., 2006; Endrizzi, 2009), which has a number of advantages for a wide range of permafrost applications. It simulates hydrological fluxes from the energy balance in complex terrain with snow-covered and snow-free regimes (e.g. Simoni et al., 2008; Endrizzi and Marsh, 2010, Endrizzi et al., 2014). Soil temperature and moisture dynamics are simulated using a robust and energy-conserving model of freezing in variably saturated soil (Dall'Amico et al., 2011). It invokes a relation between the soil-freezing characteristic and the soil water characteristic and assumes a rigid soil scheme without change in volume for water phase transition (Kurylyk and Watanabe, 2013). The model's versatility enables the user to investigate the responses of permafrost degradation on the QTP, where permafrost is characterized as a thick and stratified active layer with pronounced hydraulic dynamics due to the rainfall-evaporation-dominated land surface fluxes. In this study, we apply a one-dimensional (1-D) model at a single site, where the spatial factors, e.g. topography and snow, are not important. A proper representation of subsurface processes is essential for our research questions. Details are introduced in the following subsections.

\subsection{Model set-up}

Considering the features of land surface energy exchange and subsurface hydraulic and thermal dynamics at the study site, a 1-D conceptualized model was set up with GEOtop. The soil profile domain was generated with element size of $10 \mathrm{~cm}$ for the shallow soils $(0-3.0 \mathrm{~m})$, reducing to $0.5 \mathrm{~m}$ and $1.0 \mathrm{~m}$ for the underlying soils. There are 63 elements in total. In order to solely diagnose the effect of the stratified active layer on permafrost degradation, model simulations were driven by the same atmospheric forcing. In addition, some assumptions for this model include (1) no lateral flows exist like surface run-off and subsurface groundwater flow, (2) surface features like vegetation, soils and associated parameterization are constant in the long-term simulations. This might lead to certain deviations in the simulated results. 


\subsubsection{Input parameters}

The required climate forcing for the GEOtop models includes precipitation (snow and rain), air temperature, wind speed, relative humidity and incoming short and longwave radiation. The bottom boundary conditions for energy and water balance are set as follows. Considering the weak impact of the bottom mudstone on surface water flux, the bottom drainage rate through the mudstone was simply set to zero. While the bottom thermal condition is essential to the permafrost warming rate, as well as surface energy fluxes. The geothermal flux at the depth of $30 \mathrm{~m}$ was determined from the measured ground temperature gradient $\left(0.07{ }^{\circ} \mathrm{C} \mathrm{m}^{-1}\right)$ and estimated thermal conductivity of the mudstone. Given a thermal conductivity of soil particles $2.0 \mathrm{~W} \mathrm{~m}^{-1} \mathrm{~K}^{-1}$ and a porosity of 0.2 for the mudstone, the geothermal flux at the bottom boundary was set to $0.14 \mathrm{~W} \mathrm{~m}^{-2}$. This high geothermal flux is consistent with other observed values in the same Kunlun Mountains area (Wu et al., 2010).

Taking the analysis of the sensitivities and uncertainties of the GEOtop in mountain environments by Gubler et al. (2013) into account, we set the following surface and subsurface parameters based on field observations and relevant literature without doing any site-specific sensitivity analysis. The vegetation coverage for the sparsely vegetated ground surface was set to 0.3 and the surface roughness length, used for calculating turbulent fluxes, to $120 \mathrm{~mm}$. The latter was chosen in agreement with studies on the QTP (Ishikawa et al., 1999; Yang et al., 2008; Ma et al., 2008). They were set constant in the simulations. For subsurface, the hydraulic and thermal parameters of shallow soils $(0-3.0 \mathrm{~m})$ and underlying soils $(0.3-30.0 \mathrm{~m})$ are listed in Table 1 . More details are given as follows.

Three soil architectures of the shallow soils were used in the simulations. For the realistic case, the soil architecture (A3) consists of two layers: sandy loam $(0-0.3 \mathrm{~m})$ and coarse sand $(0.3-3.0 \mathrm{~m})$. For comparison, another two forged singlelayered architectures, A1 and A2, were employed and corresponding soil properties are the same as sandy loam and coarse sand, respectively. The required van Genuchten parameters were derived from actual soil texture information using the neural network routine (Schaap and Bouten, 1996). Soil textures for sandy loam and coarse sand are available from König (2008), while no data are available for the bottom layer of gradually weathered bedrock. Thus, hydraulic properties for the third layer are assumed to be the same as the typical clay (Domenico and Schwartz, 1990).

The soil thermal parameters of soil thermal conductivity and heat capacity were determined from the four volumetric components: water, ice, air and soil particles (Dall'Amico et al., 2011). The bulk thermal conductivity $\left(\lambda_{b}\right)$ was estimated with the following equation proposed by Cosenza at al. (2003):

$\lambda_{\mathrm{b}}=\left[(1-\phi) \sqrt{\lambda_{\mathrm{sp}}}+\theta_{\mathrm{w}} \sqrt{\lambda_{\mathrm{w}}}+\theta_{i} \sqrt{\lambda_{i}}+\theta_{\mathrm{a}} \sqrt{\lambda_{\mathrm{a}}}\right]^{2}$, where $\lambda_{\mathrm{sp}}, \lambda_{\mathrm{w}}, \lambda_{\mathrm{i}}$ and $\lambda_{\mathrm{a}}$ are thermal conductivities of soil particles, water, ice and air, respectively; $\phi$ is soil porosity; $\theta_{\mathrm{w}}, \theta_{\mathrm{i}}$, and $\theta_{\mathrm{a}}$ are the volume fractions of water, ice and air, respectively. Thermal properties of the soil particles in Table 1 were set to common values for different soil types (Farouki, 1986).

\subsubsection{Simulation protocol}

The role of soil architecture in regulating hydraulic and thermal dynamics in the stratified active layer, as well as longterm permafrost change, was investigated with six numerical simulations in Table 2. The first three simulations used the parameters listed in Table 1, and another three used the same parameters except for the thermal conductivity of soil particles for the shallow soils, which was reduced to $2.5 \mathrm{~W} \mathrm{~m}^{-1} \mathrm{~K}^{-1}$. Thus, six simulations with corresponding model settings were projected with atmospheric forcing for a long period of 1980-2100. Besides, similar simulations were also conducted for comparison of the hydraulic and thermal pattern in 2008 by replacing the meteorological forcing with the observed air temperature and precipitation.

The atmospheric forcing used in this study was produced from the fifth Coupled Model Intercomparison Project database of GCM output (CMIP5) (Taylor et al., 2012). The projected climate scenario of the Representative Concentration Pathway 8.5 (RCP8.5) was dynamically downscaled using the CanESM2/CGCM4 model (Verseghy, 1991), which corresponds to a usual warming scenario with $8.5 \mathrm{~W} \mathrm{~m}^{-2}$ forcing by 2100 . Figure 2 provides the projected changes in mean annual air temperature (MAAT) and annual total precipitation from 1900 to 2100 . Generally, a pronounced increase in air temperature started in the 1980s and there is also a noticeable change in precipitation. These features are generally consistent with the regional trend of air temperature and precipitation obtained from local observations (Guo and Wang, 2013; Hu et al., 2014). Considering the rapid warming in permafrost during the past few decades (Cheng and $\mathrm{Wu}, 2007)$, a reasonable hypothesis is to presume the climate was steady for the 80 years before the 1980s. Accordingly, we assume that the thin permafrost around the 1980s was in pseudo equilibrium. Therefore, the model was spun up with the atmospheric forcing by using a repeated 10 -year period from 1970 to 1979 that kept the mean annual soil temperature change less than $0.01^{\circ} \mathrm{C}$ in all soil layers. The initial condition for the spin-up was a constant ground temperature of $-0.5{ }^{\circ} \mathrm{C}$ and water pressure in static equilibrium with a water table at $1.0 \mathrm{~m}$ below ground. 
Table 1. Soil properties of shallow soils (A: 0-3.0 m) and underlying soils (B: $3.0-30 \mathrm{~m})$ for three soil profiles (A1/B, A2/B and A3/B). $K_{\mathrm{S}}$ is saturated hydraulic conductivity, $\alpha$ and $n$ are van Genuchten parameters, $\theta_{\mathrm{r}}$ and $\theta_{\mathrm{S}}$ are residual and saturated soil water content, respectively, $\lambda_{\mathrm{sp}}$ is thermal conductivity of soil particles and $C$ is thermal capacity.

\begin{tabular}{|c|c|c|c|c|c|c|}
\hline \multicolumn{2}{|c|}{ Soil architecture } & \multirow{2}{*}{$\begin{array}{l}\text { A1 } \\
0-3.0 \mathrm{~m}\end{array}$} & \multirow{2}{*}{$\begin{array}{l}\mathrm{A} 2 \\
0-3.0 \mathrm{~m}\end{array}$} & \multicolumn{2}{|c|}{ A3 } & \multirow{2}{*}{$\begin{array}{l}\text { B } \\
3.0-30 \mathrm{~m}\end{array}$} \\
\hline & & & & $0-0.3 \mathrm{~m}$ & $0.3-3.0 \mathrm{~m}$ & \\
\hline \multirow[t]{3}{*}{ Soil texture \% } & sand & 66.3 & 92.2 & 66.3 & 92.2 & - \\
\hline & silt & 12.0 & 3.8 & 12.0 & 3.8 & - \\
\hline & clay & 21.7 & 4.0 & 21.7 & 4.0 & - \\
\hline \multirow[t]{5}{*}{ Hydraulic properties } & $K_{\mathrm{S}}\left(\mathrm{m} \mathrm{d}^{-1}\right)$ & 0.19 & 4.68 & 0.19 & 4.68 & $2.2 \times 10^{-3}$ \\
\hline & $\alpha\left(\mathrm{cm}^{-1}\right)$ & 0.03 & 0.03 & 0.03 & 0.03 & 0.01 \\
\hline & $n(-)$ & 1.33 & 2.85 & 1.33 & 2.85 & 1.5 \\
\hline & $\theta_{\mathrm{r}}\left(\mathrm{m}^{3} \mathrm{~m}^{-3}\right)$ & 0.06 & 0.05 & 0.06 & 0.05 & 0.10 \\
\hline & $\theta_{\mathrm{s}}\left(\mathrm{m}^{3} \mathrm{~m}^{-3}\right)$ & 0.38 & 0.38 & 0.38 & 0.38 & 0.2 \\
\hline \multirow[t]{2}{*}{ Thermal properties } & 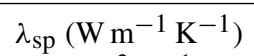 & \multirow{2}{*}{\multicolumn{4}{|c|}{$2 \times 10^{6}$}} & 2.0 \\
\hline & $\mathrm{C}\left(\mathrm{J} \mathrm{m}^{-3} \mathrm{~K}^{-1}\right)$ & & & & & $2 \times 10^{0}$ \\
\hline
\end{tabular}

Table 2. Six simulations with different combinations of soil architecture and thermal conductivity of soil particles $\left(\lambda_{\mathrm{sp}}\right)$ for the shallow soils $(0-3.0 \mathrm{~m})$. A1, A2 and A3 stand for three types of soil architecture in Table 1.

\begin{tabular}{llll}
\hline$\lambda_{\mathrm{sp}}\left(\mathrm{W} \mathrm{m}^{-1} \mathrm{~K}^{-1}\right)$ & \multicolumn{3}{l}{ Soil architecture } \\
\hline & A1 & A2 & A3 \\
5.0 & 1 & 2 & 3 \\
2.5 & 4 & 5 & 6 \\
\hline
\end{tabular}
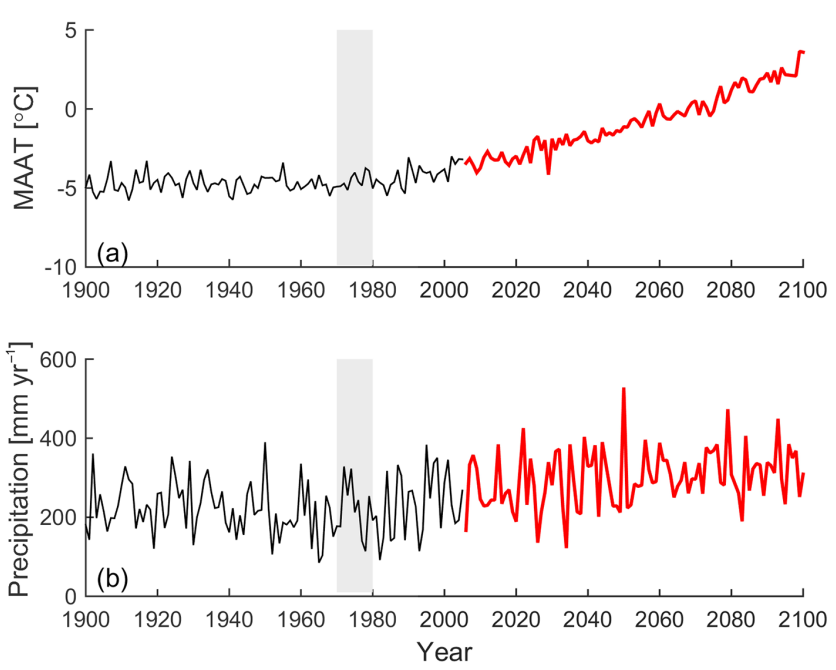

Figure 2. Time series of projected mean annual air temperature (MAAT) (a) and annual total precipitation (b) from 1900 to 2100. The black section represents historical data and the red section represents projected data. The period in shadow (1970-1979) was repeatedly used for spin-up.

\section{Results and discussion}

\subsection{Relationship between air temperature and near-surface soil temperature}

Figure 3 shows the relationship between daily mean air temperature and near-surface soil temperature $(5 \mathrm{~cm}$ below ground surface) over the period of 2006-2014. A few sporadic outliers are related to abrupt cold weather, e.g. summer/autumn freezing. The linear fit indicates that the freezethaw process does not exert significant impact on heat transfer in the very shallow subsurface, which means a small change in seasonal thermal properties. This might be attributed to the seasonal total water change. In addition, the average temperature difference was about $5.0^{\circ} \mathrm{C}$, while the mean annual air temperature was even higher than $-5.0^{\circ} \mathrm{C}$. Thus, the mean annual near-surface temperature should fluctuate around $0{ }^{\circ} \mathrm{C}$.

\subsection{Surface and thermal offsets}

Figure 4 shows the mean annual thermal profiles measured over the period of 2007-2013 from $1.5 \mathrm{~m}$ above ground surface to $2.18 \mathrm{~m}$ in subsurface. The interaction between the lower atmosphere and permafrost can be characterized with surface and thermal offsets (Smith and Riseborough, 2002). Limited by available measurements, surface offsets were approximately estimated from the difference between mean annual near-surface $(10 \mathrm{~cm})$ temperature (MAGST) and MAAT, and the thermal offsets were calculated from the difference between mean annual temperature (MAT) close to the permafrost table $(2.18 \mathrm{~m})$ and MAGST. Here we should mention that these thermal offsets were overestimated slightly due to the used bottom MAT, which is not exactly at the permafrost table. Calculations show that the surface offsets in 2008, 2009 and 2013 were $4.40,3.78$ and $4.30^{\circ} \mathrm{C}$, re- 


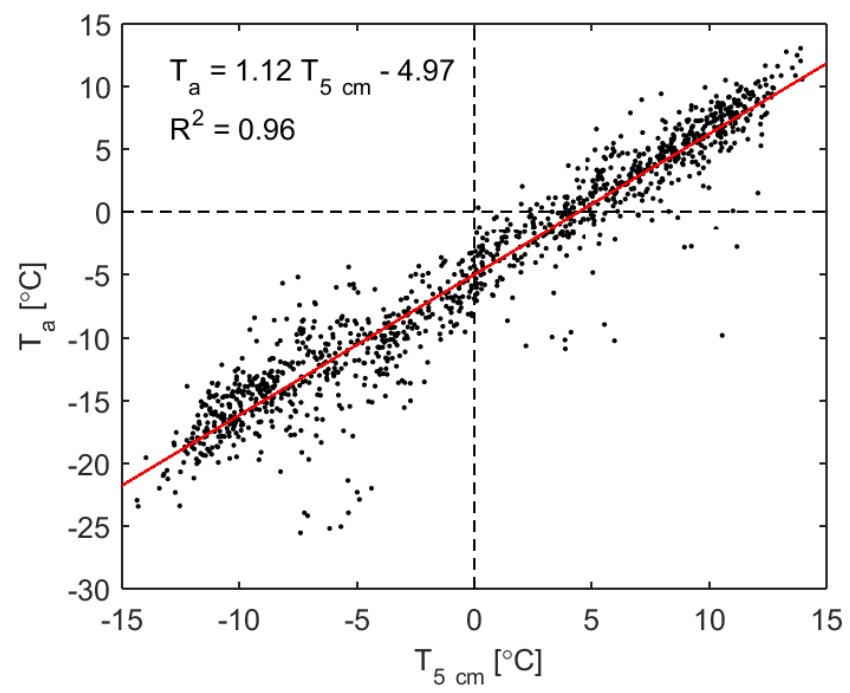

Figure 3. Relationship between the daily mean air temperature $\left(T_{\mathrm{a}}\right)$ and near-surface soil temperature $\left(T_{5 \mathrm{~cm}}\right.$, measured at $5 \mathrm{~cm}$ below the ground surface) over the period from 2006 to 2014.

spectively. These values indicate a weak coupling between the lower atmosphere and ground surface. While the thermal offsets changed from positive values, i.e. $0.47^{\circ} \mathrm{C}(2007)$ and $0.33^{\circ} \mathrm{C}(2008)$ to negative ones, $-0.18^{\circ} \mathrm{C}$ (2009) and $-0.15^{\circ} \mathrm{C}$ (2013). Surprisingly, the positive thermal offsets occurred in colder weather conditions. A similar phenomenon has been found in a nearby region by Lin et al. (2015). This result seems to conflict with the fact that permafrost commonly exhibits a negative thermal offset (Smith and Riseborough, 2002). This might be related to the unique hydraulic and thermal dynamics in the active layer, which can cause reversed seasonally variable thermal conductivity.

\subsection{Pattern of hydraulic and thermal regimes in the stratified active layer}

Figure 5 shows a typical annual evolution of the active layer to the weather condition (MAAT is $-4.40{ }^{\circ} \mathrm{C}$ and total rain $316 \mathrm{~mm}$ ) in 2008. Figure 5a reflects a typical climate regime with dominant rainfall in the rainy season from June to September on the north-eastern QTP. Note that the precipitation measurements mainly include rainfall, and light snowfall was detected by an acoustic sensor to measure distance change. Figure $5 \mathrm{~b}$ shows the active layer during an annual freeze-thaw cycle. The distribution of liquid soil water indicates that a large amount of suprapermafrost groundwater existed during the period from late May to the end of January with a maximum thickness of this saturated layer in excess of $1 \mathrm{~m}$. The groundwater table roughly fluctuated around $1.0 \mathrm{~m}$ below the ground surface and was mainly recharged by rainfall infiltration during the thawing period (late April to late October).

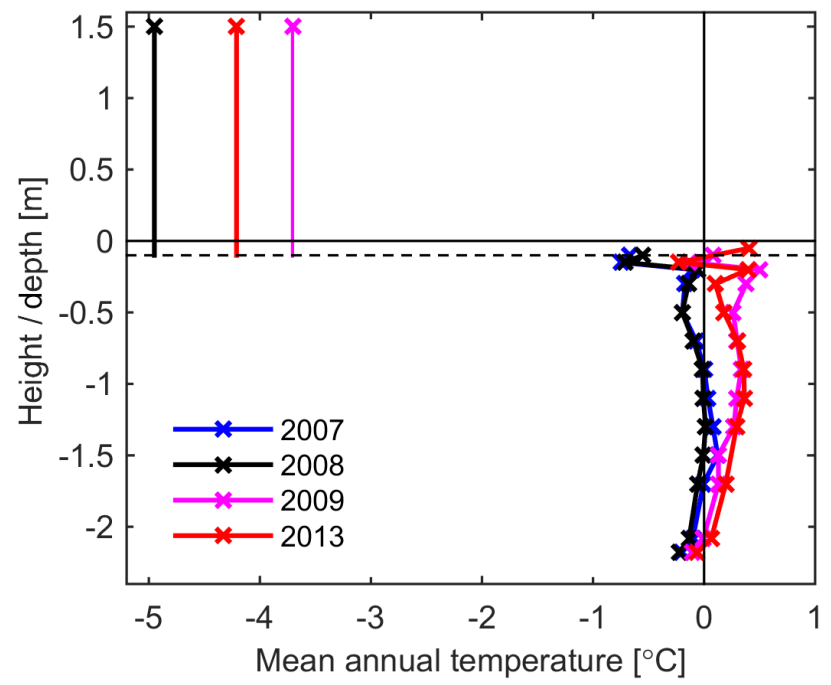

Figure 4. All available thermal profiles from 2007 to 2013. The temperatures at $1.5 \mathrm{~m}$ are the mean annual air temperatures (MAAT). Note: missing years were caused by data gaps.
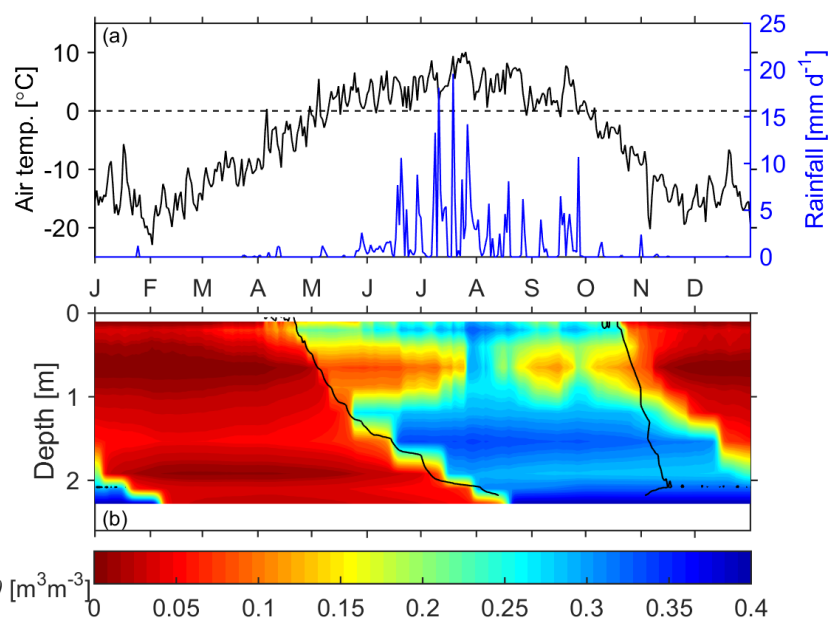

Figure 5. Typical dynamics of the active layer during an annual cycle (data from 2008). (a) Daily mean air temperature and daily rainfall. (b) Liquid water content (colours) and $0^{\circ} \mathrm{C}$-isotherm (black line).

A noteworthy pattern of the water content distribution is the dry interlayer around $0.7 \mathrm{~m}$. This layer was occasionally wetted by rain infiltration during the rainy season, but otherwise was rather dry, as was also the case during the freezing period. This situation results from a fine-textured and less permeable layer overlying a coarse-textured one. We anticipate that the seasonal contrast in total soil water (reduction from the thawing period to the freezing period) in this dry layer will modify the seasonal thermal properties of the active layer. 


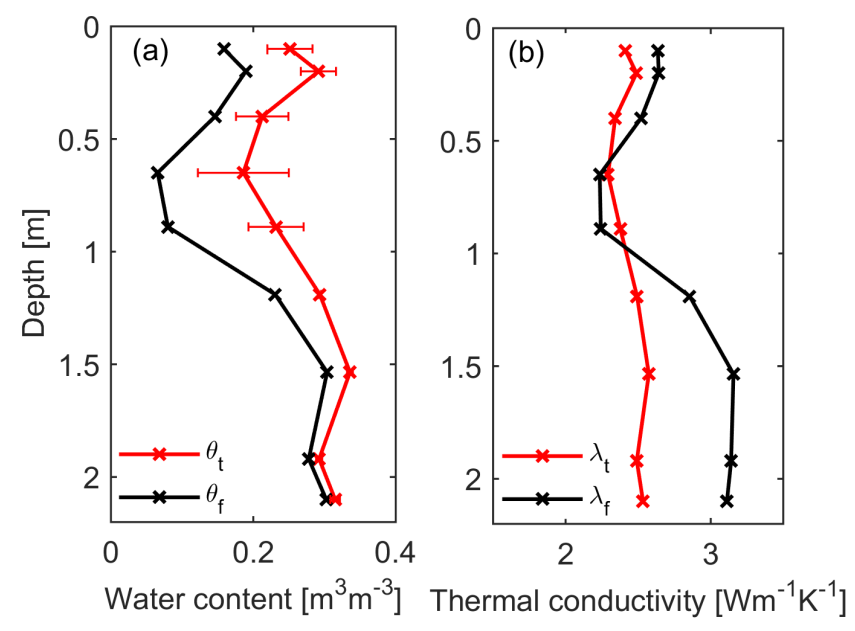

Figure 6. Seasonal change in soil water content (a) and thermal conductivity (b) calculated with Eq. (1) in the thick active layer in 2008. $\theta_{\mathrm{t}}$ and $\theta_{\mathrm{f}}$ are the mean total water content during the summer period and winter period, respectively, and $\lambda_{t}$ and $\lambda_{f}$ are the corresponding thermal conductivities.

Table 3. Interannual variation of the maximum seasonal thermal conductivity ratio $\left(\lambda_{\mathrm{t}} / \lambda_{\mathrm{f}}\right)$ in the monitoring profile. ${ }^{*}$ Hydrological year occurs from 1 May to 30 April.

\begin{tabular}{llllllll}
\hline Year* & 2007 & 2008 & 2009 & 2010 & 2011 & 2012 & 2013 \\
\hline$\lambda_{\mathrm{t}} / \lambda_{\mathrm{f}}$ & 0.99 & 1.01 & 1.01 & 0.97 & - & 1.00 & 0.90 \\
\hline
\end{tabular}

\subsection{Effect of seasonal total water content reduction on the ratio of thermal conductivity}

For active layers with mineral soils, the ratio of thermal conductivity in the thawed and frozen states $\left(\lambda_{t} / \lambda_{\mathrm{f}}\right)$ is assumed to be less than or equal to one (Riseborough and Smith, 1998). However, the factor of seasonal total water content reduction is not negligible at our study site. Figure 6a compares the change in total water content between summer and winter in 2008. The maximum seasonal water content reduction occurred around $0.7 \mathrm{~m}$ in the active layer. Assuming a thermal conductivity of $5.0 \mathrm{~W} \mathrm{~m}^{-1} \mathrm{~K}^{-1}$ for the sand with high content of quartz, the thermal conductivities at different depths were calculated with Eq. (1) in Fig. 6b. There are two locations with $\lambda_{\mathrm{t}}>\lambda_{\mathrm{f}}$ at 0.65 and $0.89 \mathrm{~m}$ depth. Significant reduction of the total water content also occurred at other depths, all accompanied by corresponding reductions of $\lambda_{\mathrm{f}}$. The interannual variation of the maximum $\lambda_{t} / \lambda_{\mathrm{f}}$ in the profile is listed in Table 3. In most years, it is very close to or over 1, e.g. 2008 and 2009. The smaller value 0.90 in 2013 is attributed to the wet year with extraordinary rainfall.

In order to exceed the ratio of 1 , the seasonal total water content has to fall below a certain threshold, which depends on soil thermal conductivity and water content in a thawed state. For instance, the soils with high thermal conductivity
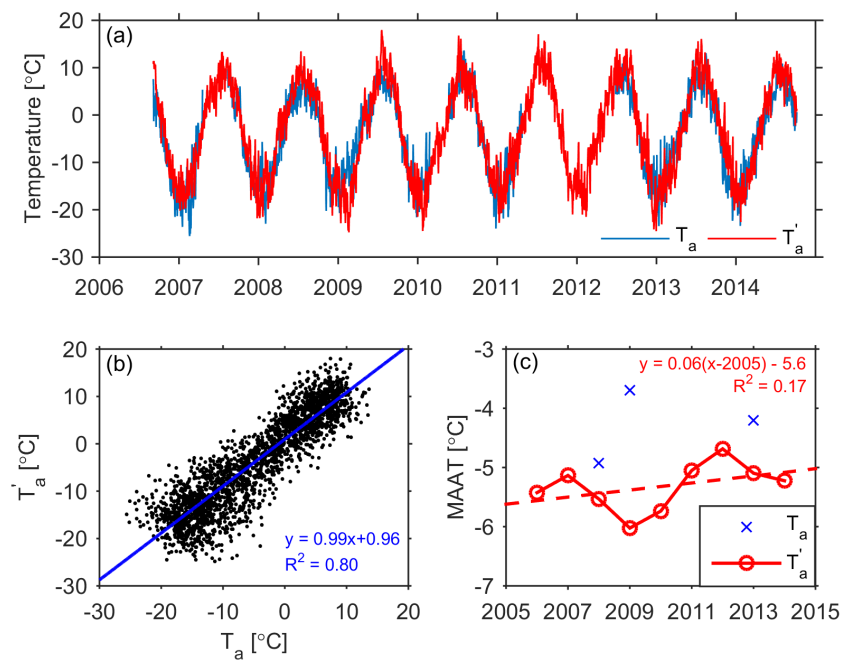

Figure 7. Air temperature change over the period of 2006-2014. (a) Comparison of observed and projected daily averaged air temperature $\left(T_{\mathrm{a}}\right.$ and $\left.T_{\mathrm{a}}^{\prime}\right)$. (b) Relationship between $T_{\mathrm{a}}$ and $T_{\mathrm{a}}^{\prime}$ with a linear regression. (c) Comparison of the observed and projected annual mean air temperature (MAAT) after correction with (b). A linearfitted (dashed line) warming rate of $0.07^{\circ} \mathrm{C} \mathrm{yr}^{-1}$ is derived from the projected one.

of soil particles will need larger total water content reduction than the soils with small thermal conductivity of soil particles. However, given the same amount of total water content reduction, the soils with a low soil water content in thawed state will be prone to reach a ratio over 1 . Generally, the soil water content condition in a thawed state depends on soil type and soil structure. Considering the unique precipitation characteristics on the QTP, seasonal total water content reduction is common in this kind of permafrost region. Unfortunately, the role of soil architecture in thermal conductivity parameterization has been rarely addressed to date.

\subsection{Comparison of observed and simulated permafrost warming rates}

In this section, the model was validated by comparing with the observations. Figure 7 compares the observed and CMIP5-projected air temperature over the period of 20062014. Generally, the patterns are very similar in Fig. 7a, but there is a daily averaged upshift of $0.96^{\circ} \mathrm{C}$ of the projected values according to the linear regression of all available values (Fig. 7b). Since there were several data gaps in the observed air temperature, it is difficult to derive a trend of the measured MAAT change in Fig. 7c. However, a linear-fitted warming rate of $0.07^{\circ} \mathrm{Cyr}^{-1}$ of the projected MAAT from 2006 to 2100 can be derived from Fig. 2a.

Figure 8 compares the observed and simulated permafrost temperature changes over the period from 2006 to 2014. The measured temperature $T_{\mathrm{obs}, 06}$ was taken from a shallow borehole on 30 August 2006 and $T_{\mathrm{obs}, 14}$ was from a 


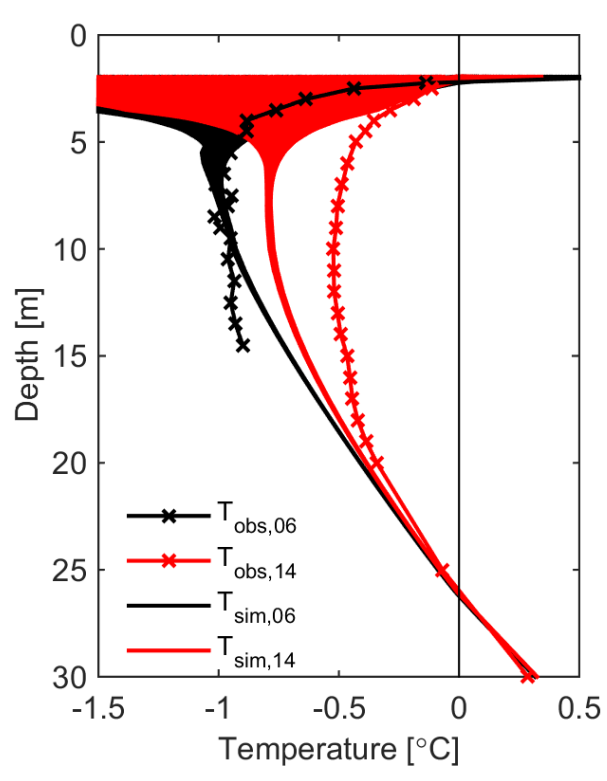

Figure 8. Comparison of observed and simulated permafrost temperature changes at the Chumaer site over the period from 2006 to 2014. The measured temperatures, $T_{\mathrm{obs}, 06}$ and $T_{\mathrm{obs}, 14}$, were taken from a shallow borehole and a nearby deep borehole on 30 August 2006 and 22 February 2014, respectively, while the simulated ones $T_{\text {sim, } 06}$ and $T_{\text {sim, } 14}$ show all values from the corresponding years.

nearby deep borehole on 22 February 2014. Here we assume that permafrost ground temperature distribution was roughly uniform within a small area $(30 \mathrm{~m} \times 30 \mathrm{~m})$ due to similar surface and subsurface properties. Thus, permafrost warming can be deduced from ground temperature change from the boreholes. Considering the small annual fluctuation of ground temperature change at the depth of $10 \mathrm{~m}$, two corresponding measurements irregularly conducted once a year in 2006 and 2014 can roughly provide a permafrost warming rate of $0.05 \pm 0.1^{\circ} \mathrm{C} \mathrm{yr}^{-1}, \mathrm{y}$ assuming a constant warming rate in permafrost temperature at the depth of about $10 \mathrm{~m}$, a value of $0.02{ }^{\circ} \mathrm{C} \mathrm{yr}^{-1}$ was calculated from $T_{\text {sim, }, 06}$ and $T_{\text {sim, } 14}$. This is just about half of the observed one. Compared to the projected warming rate of air temperature at the same pe$\operatorname{riod}\left(0.07{ }^{\circ} \mathrm{C} \mathrm{yr}^{-1}\right)$, the simulated warming rate is underestimated.

The evident discrepancy between observed and simulated permafrost warming rate is mainly attributed to the following three factors. First, snow process is not represented reasonably in the model due to the limitation of the meteorological forcing. Permafrost is extremely sensitive to snow cover, which has a much higher albedo $(>0.9)$ than regular ground surface $(0.1-0.4)$. Field observations show that snow cover only lasts a few weeks in pre-/post-winter, and the missing snow cover is mainly caused by evaporation and sublimation during the diurnal thawing. However, the projected meteorological data are in daily resolution and the precipitation is also not generally accurate. Second, the atmospheric forcing was downscaled from large-scale climate modelling, and it differs from site observations. In particular, the observed increasing rainfall and lower amount of snowfall are not well predicted in the projected meteorological forcing. Third, the model, using the van Genuchten parameters derived from neural network routines, had difficulty reproducing the site-specific water dynamics in the active layer and it resulted in smaller ratios of seasonal thermal conductivity compared to observed ones. Nevertheless, the model can reasonably mimic hydraulic and thermal regimes and current permafrost thermal status, and can help us to investigate the effect of the stratified active layer on permafrost warming.

\subsection{Role of the stratified thick active layer in permafrost warming}

In this section, the effect of the stratified active layer on permafrost warming was investigated with modelling, and subsurface controlling factors in the active layer including soil architecture and thermal conductivity of soil particles were examined with thermal offset and permafrost temperature. Sect. 3.6.1 demonstrates the simulated hydraulic and thermal pattern in the active layers, and Sects. 3.6.2 and 3.6.3 present the evolution of the unique thermal offset and permafrost temperature, respectively.

\subsubsection{Simulated hydraulic and thermal pattern in the active layers}

Given a typical observed meteorological forcing in 2008, the simulated hydraulic and thermal patterns of the active layers with different soil architectures (A1, A2 and A3) in 2008 are shown in Fig. 9. Generally, the thermal conductivity of the soil particles dominates the active layer thickness, regardless of the soil architecture. However, the soil hydraulic patterns are controlled by hydraulic properties (mainly soil architectures here) and influence the active layer thickness. Notice that the order of the maximum thawing depth is $\mathrm{A} 3>\mathrm{A} 1>\mathrm{A} 2$, which is similar in both panels. In addition, the one with realistic soil architecture, A3 in Fig. 9c, presents a similar hydraulic and thermal pattern to the one observed (Fig. 9c'), and this shows also that the model can reasonably capture the hydraulic and thermal dynamics in the active layer. However, the simulated downward thawing in early summer is slower than the observed one. This is mainly related to the different soil water content distributions between observed and simulated. The overestimated soil water storage in the shallow layer in the simulation lagged its thawing rate.

\subsubsection{Evolution of the unique thermal offset}

Based on the above different hydraulic and thermal patterns we investigated the impact of soil architecture on the warming of the underlying permafrost by using the thermal offset. Figure 10 shows the evolution of the thermal offset with 

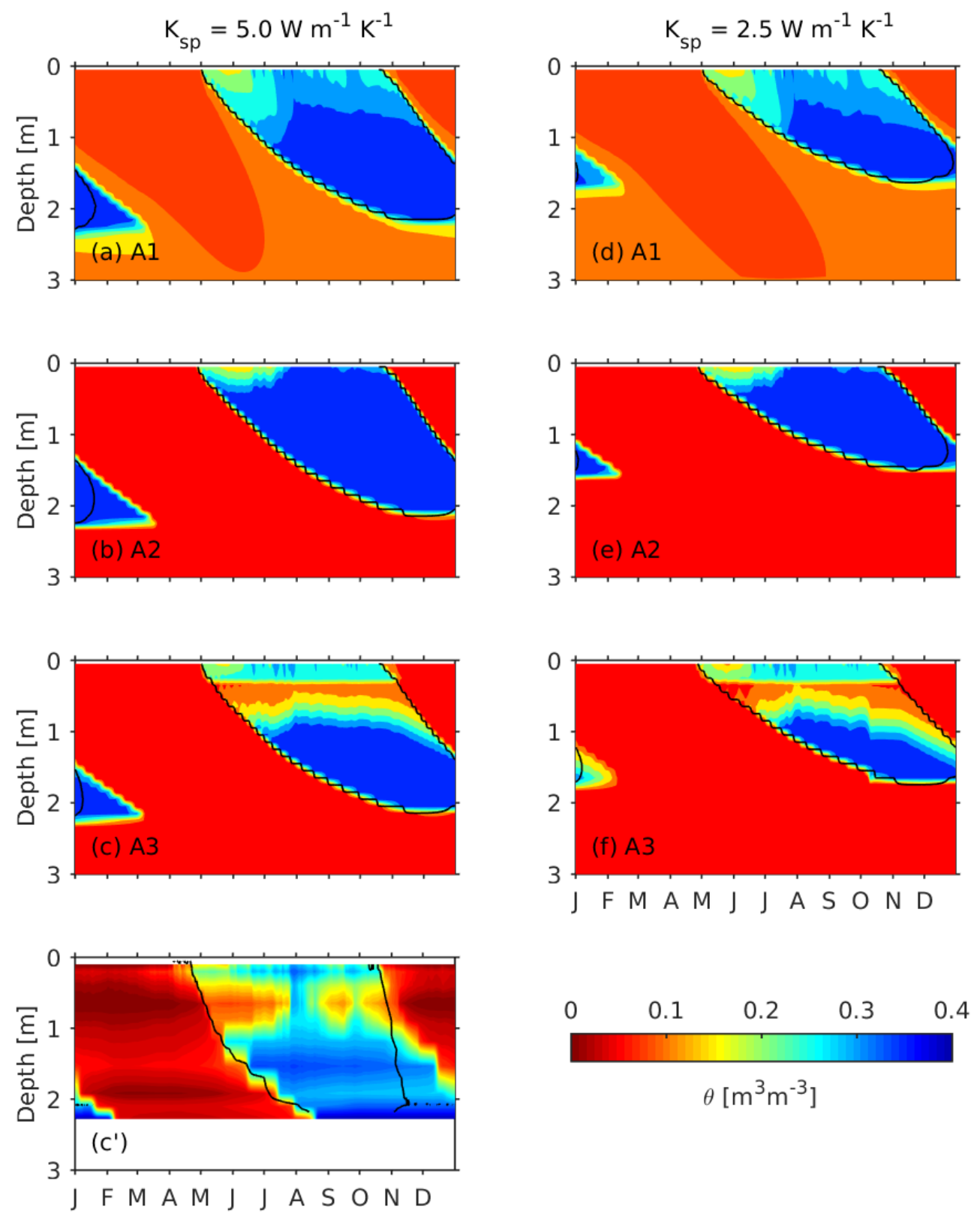

Figure 9. Comparison of the simulated unfrozen soil water content (colour) and the $0^{\circ} \mathrm{C}$-isotherm (black line) in the active layer with different soil architectures and thermal conductivities $\left(\lambda_{\mathrm{sp}}\right)$ in 2008. The rows correspond to different architectures of the soil: (a,d) single fine-grained

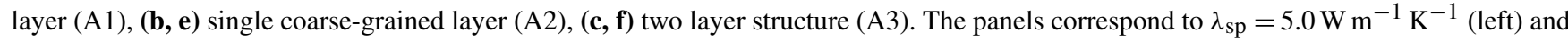
$\lambda_{\mathrm{sp}}=2.5 \mathrm{~W} \mathrm{~m}^{-1} \mathrm{~K}^{-1}$ (right). (c') Observed case (same as Fig. 5b).

the change of MAAT; the latter the result of climate warming. The thermal offset is calculated as the annual temperature difference $\left(T_{\text {top }}-T_{0.1 \mathrm{~m}}\right)$ between the top of the permafrost table and the near-surface $(0.1 \mathrm{~m})$ and disappears when talik presents, disconnecting the permafrost from the seasonal frost layer. Generally, all the thermal offsets decrease with increasing MAAT. However, the thermal offsets of A3 in Fig. 10a and b are both positive at the beginning of the simulation, when the permafrost is close to thermal equi- librium, whereas the thermal offset of A2 is always negative and the thermal offset of $\mathrm{A} 1$ is in between $\mathrm{A} 2$ and $\mathrm{A} 3$.

Thermal offset (TTOP-MAGST) originates from different heat transfer efficiencies of an active layer between summer and winter in a permafrost region at equilibrium state. These mainly result from thermal conductivity of ice being 4 times that of water. With this, the annual mean temperature profile is shifted towards the summer profile and the thermal offset is typically negative. Its value is modified by several 


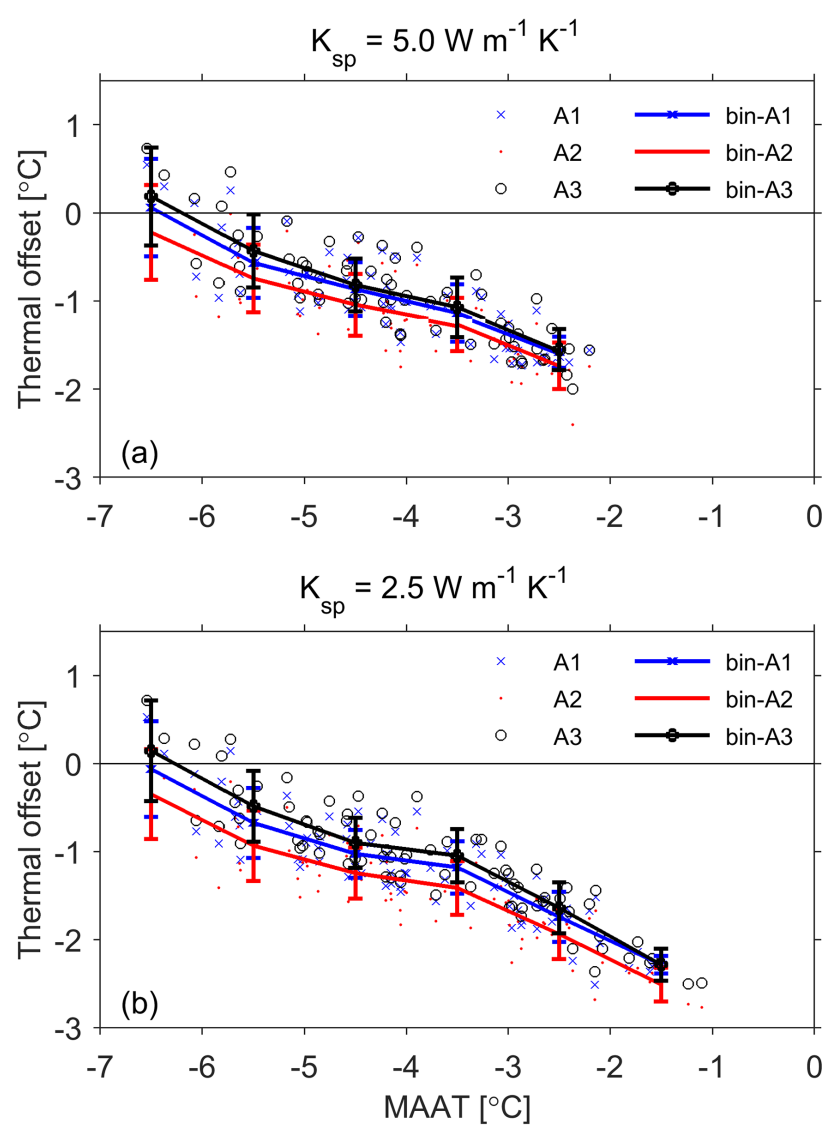

Figure 10. Thermal offset as a function of mean annual air temperature (MAAT) obtained from the simulations for the period 19802100 of the three soil architectures, A1, A2 and A3. The lines connect the means of $1.0^{\circ} \mathrm{C}$-bins, the bars indicate the corresponding standard deviations. The upper frame is for $\lambda_{\mathrm{sp}}=5.0 \mathrm{~W} \mathrm{~m}^{-1} \mathrm{~K}^{-1}$, the lower one for $\lambda_{\mathrm{sp}}=2.5 \mathrm{~W} \mathrm{~m}^{-1} \mathrm{~K}^{-1}$.

aspects, for instance it is decreased through snow cover and increased by a soil water content that is higher in summer than in winter. For instance, the positive thermal offset at equilibrium state in Fig. 10 was mainly led by the high ratio of $\lambda_{t} / \lambda_{f}$ around 1 via seasonal water content reduction. This phenomenon is prone to appear in the thick stratified active layers on the QTP with a summer-monsoon-dominated precipitation pattern. Generally, the schematic mean annual ground temperature profile is closer to the one described by Brown (1970) than the one suggested by Smith and Riseborough (2002) as shown in Fig. 11. In addition, the concept of thermal offset will be invalid at disequilibrium conditions. For instance, the thermal offsets in Fig. 10 decrease dramatically with climate warming. It is clear that the decreasing negative thermal offsets were not caused by $\lambda_{f}>\lambda_{t}$ but by the lag between surface and subsurface warming. This is corroborated by the observed thermal offsets (Fig. 4) for which positive values occurred in 2007 and 2008 and decreased to negative values in 2009 and 2013. Therefore, the concept of

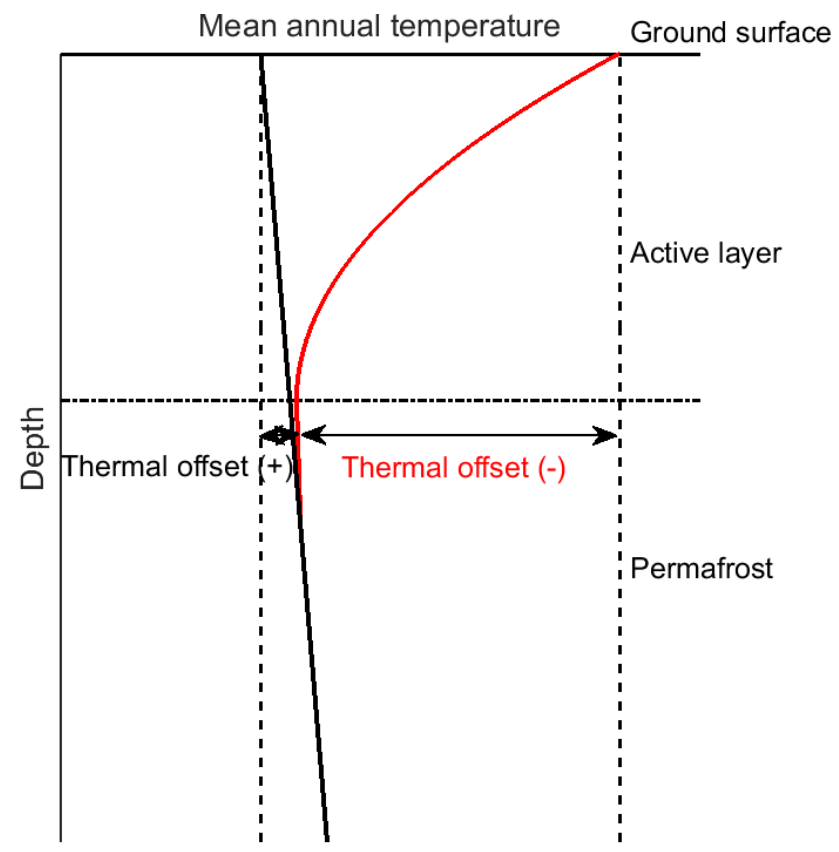

Figure 11. Schematic mean annual ground temperature for two types of permafrost. Black curve shows the studied permafrost with positive thermal offset and red curve shows common permafrost with negative thermal offset.

the normal offset is not suitable for the studied case, and the plausible "normal" thermal offset might not necessarily be attributed to $\lambda_{\mathrm{f}}>\lambda_{\mathrm{t}}$, but to permafrost disequilibrium.

\subsubsection{Subsurface factors controlling the permafrost warming rate}

Apart from the change rate of climatic forcing, the evolution of thermal regime in active layers is also not negligible for permafrost warming, and it is related to subsurface factors like thermal conductivity of soil particles and soil hydraulic properties. In particular, the thermal regime in the studied thick active layer with unique soil architecture strongly relies on the hydraulic regime. Given three different soil architectures and two different thermal conductivities of soil particles $\left(\lambda_{\mathrm{sp}}=5.0 \mathrm{~W} \mathrm{~m}^{-1} \mathrm{~K}^{-1}\right.$ and $\left.\lambda_{\mathrm{sp}}=2.5 \mathrm{~W} \mathrm{~m}^{-1} \mathrm{~K}^{-1}\right)$, the differences of the permafrost warming are shown in Fig. 12. Generally, the permafrost with a higher thermal conductivity of the matrix (left panel of Fig. 12) degrades faster than that in the right panel with a lower thermal conductivity, and the influence of soil architecture in the left panel is negligible. In contrast, the role of soil architecture emerges in the right panel, and the stratified active layer (A3) leads to a faster permafrost warming rate. This is mainly attributed to the effect of seasonal total water content change on seasonal variation of thermal conductivity. For the active layer with a high $\lambda_{\mathrm{sp}}$, the ratio of seasonal thermal conductivity is always close to 1.0, and the impact of seasonal total water content reduction 

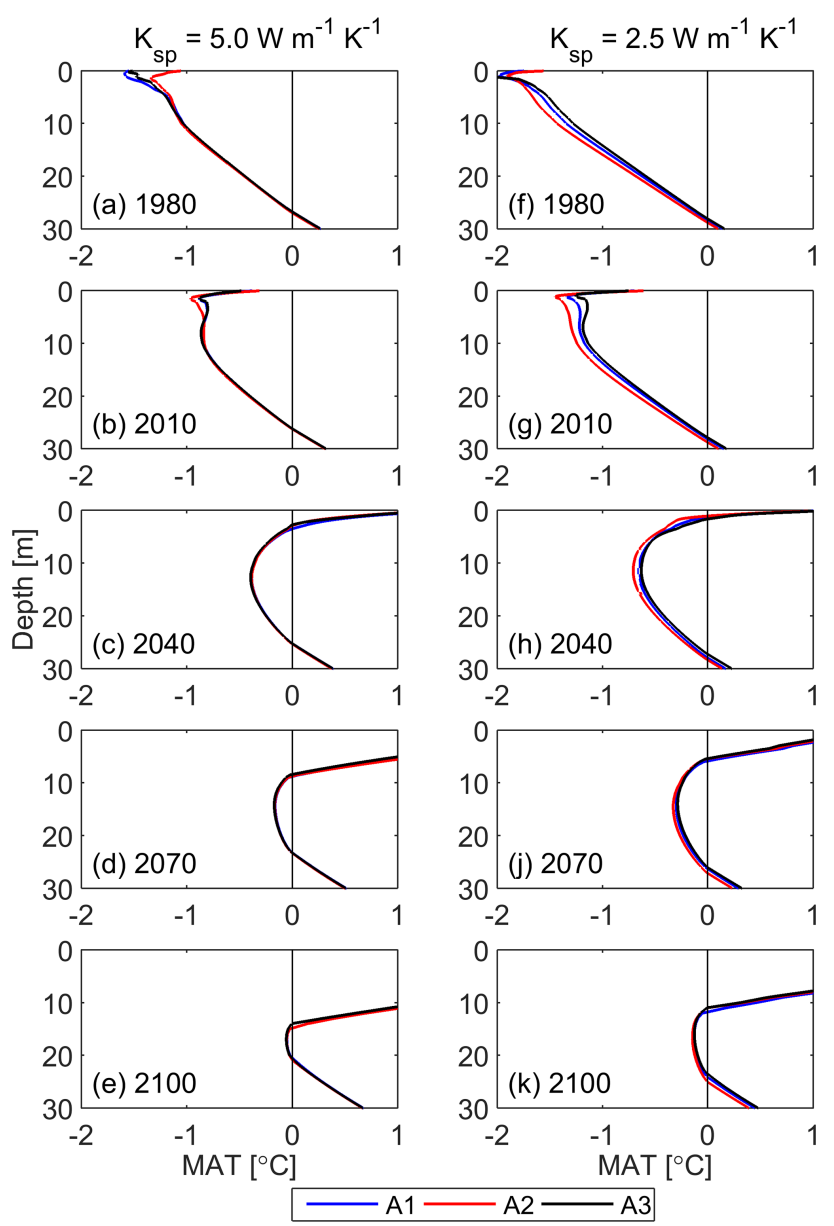

Figure 12. Comparison of the influence of soil architecture and thermal conductivity of soil particles $\left(\lambda_{\mathrm{sp}}\right)$ on permafrost degradation with simulations over the period from 1980 to 2100. (a-e) Annual mean ground temperature (MAT) of A1, A2 and A3 with a high $\lambda_{\mathrm{sp}}=5.0 \mathrm{~W} \mathrm{~m}^{-1} \mathrm{~K}^{-1}$ at selected years; $(\mathbf{f}-\mathbf{j})$ the same as $(\mathbf{a}-\mathbf{e})$ but with a low $\lambda_{\mathrm{sp}}=2.5 \mathrm{~W} \mathrm{~m}^{-1} \mathrm{~K}^{-1}$.

is rather weak. However, for the active layer with a low $\lambda_{\mathrm{sp}}$, the ratio of seasonal thermal conductivity depends strongly on the seasonal total water content reduction. Besides, soil architecture with low soil water content will have a higher ratio of seasonal thermal conductivity, given the same amount of seasonal total water content reduction.

The effects of soil architecture on permafrost warming evolve in time. First of all, the Asian summer monsoon, caused by the elevated heat source driven by the QTP (e.g. Yeh et al., 1957; Yanai et al., 1992) may not disappear in the near future, but the monsoon intensity might shift due to climate change (Duan et al., 2011). Secondly, thickening active layers can weaken the role of soil architecture in permafrost warming via exerting impact on the suprapermafrost water level as well as soil water content distribution. Given a monsoon-dominated precipitation pattern in the projected climate model data, Fig. 13 shows the evolution of
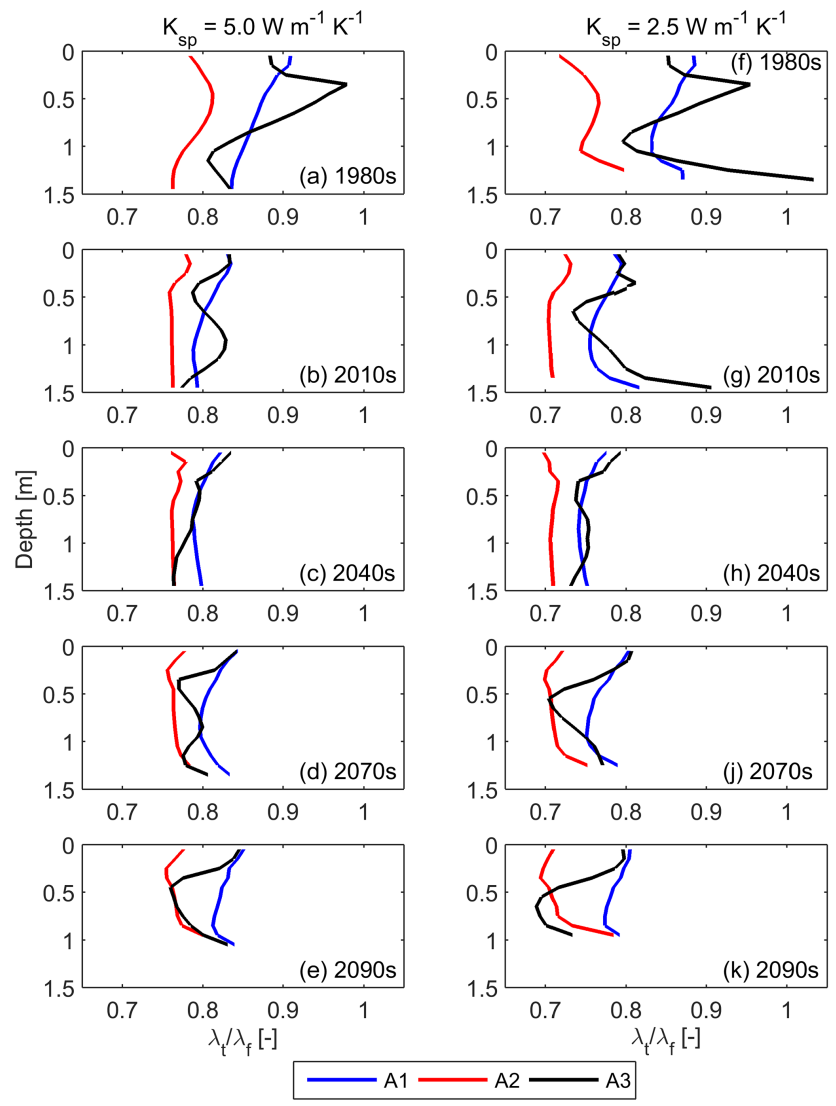

Figure 13. Comparison of the influence of soil architecture and thermal conductivity of soil particles $\left(\lambda_{\mathrm{sp}}\right)$ on the seasonal thermal conductivity ratio $\lambda_{\mathrm{t}} / \lambda_{\mathrm{f}}$ in the shallow soils over the period from 1980 to 2100 . (a-e) Decadal mean $\lambda_{t} / \lambda_{\mathrm{f}}$ of A1, A2 and A3 with a high $\lambda_{\mathrm{sp}}=5.0 \mathrm{~W} \mathrm{~m}^{-1} \mathrm{~K}^{-1}$ at selected decades; $(\mathbf{f}-\mathbf{j})$ the same as (a-e) but with a low $\lambda_{\mathrm{sp}}=2.5 \mathrm{~W} \mathrm{~m}^{-1} \mathrm{~K}^{-1}$.

seasonal $\lambda_{\mathrm{t}} / \lambda_{\mathrm{f}}$ of the shallow soils $(0-1.5 \mathrm{~m})$ over the simulating period of 1980-2100. Decadal mean $\lambda_{\mathrm{t}} / \lambda_{\mathrm{f}}$ were calculated for all the simulations. Compared to the same soil architectures but different thermal conductivities of soil particles, the maximum decadal mean $\lambda_{\mathrm{t}} / \lambda_{\mathrm{f}}$ in the left panel with $\lambda_{\mathrm{sp}}=5.0 \mathrm{~W} \mathrm{~m}^{-1} \mathrm{~K}^{-1}$ are higher than that in the right panel with $\lambda_{\mathrm{sp}}=2.5 \mathrm{~W} \mathrm{~m}^{-1} \mathrm{~K}^{-1}$. However, the differences of $\lambda_{\mathrm{t}} / \lambda_{\mathrm{f}}$ among the architectures in the right panel are bigger than in the left panel. Besides, the maximum values of $\lambda_{t} / \lambda_{\mathrm{f}}$ in A3 are bigger than the other two from the 1980s to 2040s, then they gradually become smaller. Generally, the shrinking differences in decadal mean $\lambda_{\mathrm{t}} / \lambda_{\mathrm{f}}$ among the three architectures indicate that the effects of the stratified active layers on permafrost warming are significant in the early state of permafrost degradation and will decrease afterwards. These results are all consistent with the thermal regimes in Fig. 12. 


\section{Conclusions}

In summary, this study presented an interesting case which showed the effects of stratified active layers with a high ratio of seasonal thermal conductivity, $\lambda_{\mathrm{t}} / \lambda_{\mathrm{f}} \geq 1.0$, on permafrost warming on the QTP. Key findings are listed in the following.

1. An observed extraordinary permafrost warming rate $\left(>0.5^{\circ} \mathrm{C}\right.$ per decade) was found at the study site with sparse vegetation and annual precipitation 300$400 \mathrm{~mm}$. Apart from the climate drivers and the unusual high geothermal flux from the bottom, a high ratio of seasonal thermal conductivity in the stratified active layer is instrumental in regulating the interaction between climate and permafrost.

2. Observation and simulation suggest that the concept of the thermal offset proposed by Smith and Riseborough (2002) is not suitable for the studied permafrost on the QTP. In contrast to the normal negative thermal offset caused by the low ratio of seasonal thermal conductivity, a reversed thermal offset at equilibrium state is formed due to the remarkably high ratio of seasonal thermal conductivity $(\geq 1)$.

3. Furthermore, the specific soil architecture plays a nonnegligible role in forming a dry interlayer while raising the ratio $\lambda_{\mathrm{t}} / \lambda_{\mathrm{f}}$ and resulting in a higher permafrost warming rate than the active layers with uniform soils.

Considering the importance of rainfall in the mechanism of the hydraulic and thermal dynamics in the active layers, there is no doubt that permafrost warming would be influenced by the increasing precipitation in recent years and in future on the QTP. Consequently, soil hydraulic properties, particularly soil architecture, become more and more important for the thermal conductivity parameterization in land surface and permafrost modelling. In particular, the empirical permafrost models using a ratio of seasonal thermal conductivity smaller than 1.0 might underestimate the effect of climate warming. However, this study is mainly based on a specific site. More field investigations are required to reveal the regional difference in permafrost degradation over the QTP.

Acknowledgements. We acknowledge Yanhui You for field data collection and Liang Chen for processing climate data. This research was funded in part by the National Natural Science Foundation of China (Grant No. 41171059). The authors thank the anonymous reviewers for constructive feedback on the manuscript.

Edited by: M. Schneebeli

Reviewed by: S. Endrizzi and two anonymous referees

\section{References}

Burn, C. R. and Smith, C. A. S.: Observations of the "thermal offset" in near-surface mean annual ground temperatures at several sites near Mayo, Yukon Territory, Canada, Arctic, 41, 9-104, 1988.

Brown, R. J. E.: Permafrost in Canada: its influence on northern development, University of Toronto Press, Toronto, 1970.

Cheng, G. and $\mathrm{Wu}, \mathrm{T}$.: Responses of permafrost to climate change and their environmental significance, Qinghai-Tibet Plateau, J. Geophys. Res., 112, F02S03, doi:10.1029/2006JF000631, 2007.

Cosenza, P., Guerin, R., and Tabbagh, A.: Relationship between thermal conductivity and water content of soils using numerical modelling, Eur. J. Soil Sci., 54, 581-587, 2003.

Dall'Amico, M., Endrizzi, S., Gruber, S., and Rigon, R.: A robust and energy-conserving model of freezing variably-saturated soil, The Cryosphere, 5, 469-484, doi:10.5194/tc-5-469-2011, 2011.

Domenico, P. A. and Schwartz, F. W.: Physical and Chemical Hydrogeology, John Wiley \& Sons, New York, 824 pp., 1990.

Duan, A. M., Li, F., Wang, M. R., and Wu, G. X.: Persistent weakening trend in the spring sensible heat source over the Tibetan Plateau and its impact on the Asian summer monsoon, J. Climate, 24, 5671-5682, 2011.

Endrizzi, S.: Snow cover modelling at local and distributed scale over complex terrain, $\mathrm{PhD}$ thesis, Institute of Civil and Environmental Engineering, University of Trento, Trento, available at: http://web.unitn.it/files/download/9673/endrizzi_tesi_def.pdf (last access: 17 November 2014), 2009.

Endrizzi, S. and Marsh, P.: Observations and modeling of turbulent fluxes during melt at the shrub-tundra transition zone 1: point scale variations, Hydrol. Res., 41, 471-491, 2010.

Endrizzi, S., Gruber, S., Dall'Amico, M., and Rigon, R.: GEOtop 2.0: simulating the combined energy and water balance at and below the land surface accounting for soil freezing, snow cover and terrain effects, Geosci. Model Dev., 7, 2831-2857, doi:10.5194/gmd-7-2831-2014, 2014.

Farouki, O. T.: Thermal properties of soils, Series on Rock and Soil Mechanics, 11, 1-136, 1986.

Guo, D. and Wang, H.: Simulation of permafrost and seasonally frozen ground conditions on the Tibetan Plateau, 1981-2010, J. Geophys. Res.-Atmos., 118, 5216-5230, doi:10.1002/jgrd.50457, 2013.

Gubler, S., Endrizzi, S., Gruber, S., and Purves, R. S.: Sensitivities and uncertainties of modeled ground temperatures in mountain environments, Geosci. Model Dev., 6, 1319-1336, doi:10.5194/gmd-6-1319-2013, 2013.

Harris, C., Arenson, L. U., Christiansen, H. H., Etzelmüller, B., Frauenfelder, R., Gruber, S., Haeberli, W., Hauck, C., Hölzle, M., Humlum, O., Isaksen, K., Kääb, A., Kern-Lütschg, M. A., Matsuoka, N., Murton, J. B., Nötzli, J., Phillips, M., Ross, N., Seppälä, M., Springman, S. M., and Vonder Mühll, D.: Permafrost and climate in Europe: monitoring and modeling thermal, geomorphological and geotechnical responses, Earth-Sci. Rev, 92, 117-171, 2009.

Hasler, A., Gruber, S., and Haeberli, W.: Temperature variability and offset in steep alpine rock and ice faces, The Cryosphere, 5, 977-988, doi:10.5194/tc-5-977-2011, 2011.

Hayashi, M., Goeller, G., Quinton, W. L., and Wright, N.: A simple heat-conduction method for simulating the frost-table depth in hydrological models, Hydrol. Process., 21, 2610-2622, 2007.

Hu, Q., Jiang, D., and Fan, G.: Evaluation of CMIP5 Models over the Qinghai-Tibetan Plateau, Chinese J. Atmos. Sci., 38, 924938, 2014 (in Chinese). 
Huang, B., Gong, Z., and Gu, G.: Elemental geochemistry of altocryic soils of Qinghai-Tibet Plateau in China - An example from the unpopulated Kekexili region, Geochem. J., 40, 211218, 2006

Ishikawa, H., Hayashi, T., and Tanaka, T.: Summary and the preliminary results of PBL observation, Proceedings of the 1st International Workshop on GAME-Tibet. Xi' an, China, 11-13 January 1999, 69-72, 1999.

König, K.: Thermal dynamics of permafrost sites on the QinghaiTibet Plateau, Diploma thesis, University of Heidelberg, Heidelberg, 2008.

Kurylyk, B. L. and Watanabe, K.: Review: The mathematical representation of freezing and thawing processes in variablysaturated, non-deformable soils, Adv. Water Resour., 60, 160 177, doi:10.1016/j.advwatres.2013.07.016, 2013.

Kurylyk, B. L., MacQuarrie, K. T. B., and McKenzie, J. M.: Climate change impacts on groundwater and soil temperatures in cold and temperate regions: Implications, mathematical theory, and emerging simulation tools, Earth Sci. Rev., 138, 313-334, 2014.

Li, S. and Cheng, G.: Map of Frozen Ground on Qinghai -Xizang Plateau, Gansu Culture Press, Lanzhou, 1996.

Lin, Z., Burn, C. R., Niu, F., Luo, J., Liu, M., and Yin, G.: The thermal regime, including a reversed thermal offset, of arid permafrost sites with variations in vegetation cover density, Wudaoliang basin, Qinghai-Tibet Plateau, Permafrost Periglac., 26, 142-159, doi:10.1002/ppp.1840, 2015.

Ma, Y., Menenti, M., Feddes, R., and Wang, J.: Analysis of the land surface heterogeneity and its impact on atmospheric variables and the aerodynamic and thermodynamic roughness lengths, J. Geophys. Res., 113, D08113, doi:10.1029/2007JD009124, 2008.

Pan, X.: Hydraulic and thermal dynamics at various permafrost sites on the Qinghai-Tibet Plateau, PhD thesis, University of Heidelberg, Heidelberg, 2011.

Pan, X., You, Y., Roth, K., Guo, L., Wang, X., and Yu, Q.: Mapping permafrost features that influence the hydrological processes of a thermokarst lake on the Qinghai-Tibet Plateau, China, Permafrost Periglac., 25, 60-68, doi:10.1002/ppp.1797, 2014.

Piao, S. L., Ciais, P., Huang, Y., Shen, Z. H., Peng, S. S., Li, J. S., Zhou, L. P., Liu, H. Y., Ma, Y. C., Ding, Y. H., Friedlingstein, P., Liu, C. Z., Tan, K., Yu, Y. Q., Zhang, T. Y., and Fang, J. Y.: The impacts of climate change on water resources and agriculture in China, Nature, 467, 43-51, 2010.

Rigon, R., Bertoldi, G., and Over, T. M.: GEOtop: a distributed hydrological model with coupled water and energy budgets, J. Hydrometeorol., 7, 371-388, 2006.

Riseborough, D. W. and Smith, M. W.: Exploring the limits of permafrost, Permafrost: Seventh International Conference, Yellowknife, Canada, Proceedings, edited by: Lewkowicz, A. G. and Allard, M., Nordicana, 57, 935-942, 1998.

Romanovsky, V. E. and Osterkamp, T. E.: Interannual variations of the thermal regime of the active layer and near surface permafrost in Northern Alaska, Permafrost Periglac., 6, 313-335, doi:10.1002/ppp.3430060404, 1995.
Romanovsky, V. E., Smith, S. L., Christiansen, H. H., Shiklomanov, N. I., Streletskiy, D. A., Drozdov, D. S., Oberman, N. G., Kholodov, A. L., and Marchenko, S. S.: Permafrost (Arctic Report Card 2011), http://www.arctic.noaa.gov/report11/ (last access: 20 July 2016), 2013.

Schaap, M. G. and Bouten, W.: Modeling water retention curves of sandy soils using neural networks, Water Resour. Res., 32, 30333040, 1996.

Schuur, E. A. G., McGuire, A. D., Schädel, C., Grosse, G., Harden, J. W., Hayes, D. J., Hugelius, G., Koven, C. D., Kuhry, P., Lawrence, D. M., Natali, S. M., Olefeldt, D., Romanovsky, V. E., Schaefer, K., Turetsky, M. R., Treat, C. C., and Vonket J. E.: Climate change and the permafrost carbon feedback, Nature, 520, 171-179, doi:10.1038/nature14338, 2015.

Simoni, S., Zanotti, F., Bertoldi, G., and Rigon, R.: Modelling the probability of occurrence of shallow landslides and channelized debris flows using GEOtop-FS, Hydrol. Process., 22, 532-545, 2008.

Smith, M. W. and Riseborough, D. W.: Permafrost monitoring and detection of climate change, Permafrost Periglac., 7, 301-309, 1996.

Smith, M. W. and Riseborough, D. W.: Climate and the limits of permafrost: a zonal analysis, Permafrost Periglac., 13, 1-15, 2002.

Taylor, K. E., Stouffer, R. J., and Meehl, G. A.: An Overview of CMIP5 and the experiment design, B. Am. Meteorol. Soc., 93, 485-498, doi:10.1175/BAMS-D-11-00094.1, 2012.

Verseghy, D. L.: CLASS - a Canadian land surface scheme for GCMs. I. Soil model, Int. J. Climatol., 11, 111-133, 1991.

Wu, Q., Zhang, T., and Liu, Y.: Permafrost temperatures and thickness on the Qinghai-Tibet Plateau, Global Planet. Change, 72, 32-38, 2010.

Wu, Q., Zhang, T., and Liu, Y.: Thermal state of the active layer and permafrost along the Qinghai-Xizang (Tibet) Railway from 2006 to 2010, The Cryosphere, 6, 607-612, doi:10.5194/tc-6607-2012, 2012.

Wu, Q., Hou, Y., Yun, H., and Liu, Y.: Changes in activelayer thickness and near-surface permafrost between 2002 and 2012 in alpine ecosystems, Qinghai-Xizang (Tibet) Plateau, China, Global Planet. Change, 124, 149-155, doi:10.1016/j.gloplacha.2014.09.002, 2015.

Yanai, M., Li, C., and Song, Z.: Seasonal heating of the Tibetan Plateau and its effects on the evolution of the Asian summer monsoon. J. Meteorol. Soc. Jpn., 70, 319-351, 1992.

Yang, K., Koike, T., Ishikawa, H., Kim, J., Li, X., Liu, H., Liu, S., Ma, Y., and Wang, J.: Turbulent flux transfer over bare-soil surfaces: characteristics and parameterizations, J. Appl. Meteorol. Clim., 47, 276-290, 2008.

Yeh, T. C., Luo, S. W., and Chu, P. C.: The wind structure and heat balance in the lower troposphere over Tibetan Plateau and its surrounding, Acta Meteorol. Sin., 28, 108-121, 1957. 